\title{
PRODUCTION MANAGEMENT TO SUPPORT NEW FLAT STEEL PRODUCT MANUFACTURING FACILITY AT TYASA IN MEXICO*
}

Werner Klein ${ }^{1}$

\begin{abstract}
The Production Management solution (Level 3) covers TYASA's existing steel making plant, billet caster and new Castrip based coil production line in Ixtaczoquitlan, Mexico. It steers the order based production utilizing product routing information and corresponding process instructions for the individual processing units. A seamless material tracking along the entire production route from heat creation in the electric arc furnace down to the final coil product provides TYASA with the genealogy information customers require for flat products. At each important process step the Level 3 compares actual quality related production results with order requirements. In case of deviations from ordered quality the plant staff is guided by rule based dispositions. The highly configurable solution supports customer to operate its production plant as a smart factory in the sense of industry 4.0 .
\end{abstract}

Keywords: Production Management; Level 3; Industry 4.0; Manufacturing Execution.

1 Dipl.-Ing.(FH), Head of Sales, Production Management, Primetals Technologies Germany GmbH, Erlangen, Bavaria, Germany. 


\section{INTRODUCTION}

Our Production Management solution covers the complete business process from order entry to product shipping. This solution enables metals producers to achieve horizontal and vertical integration of their business processes, whilst boosting productivity throughout the entire supply chain.

The customized Production Management solution includes a complete set of modules, such as:

- All planning levels from Demand \& Sales Planning via Flow \& Order Planning to Detailed Scheduling

- Entire order life cycle management including production order generation, order combination, fulfillment tracking

- Production execution to monitor and control all production activities

- Quality Management \& Control to determine detailed quality status of each material, deviation management, root cause analysis and corrective actions

- Logistics to optimize all material transports and inventory

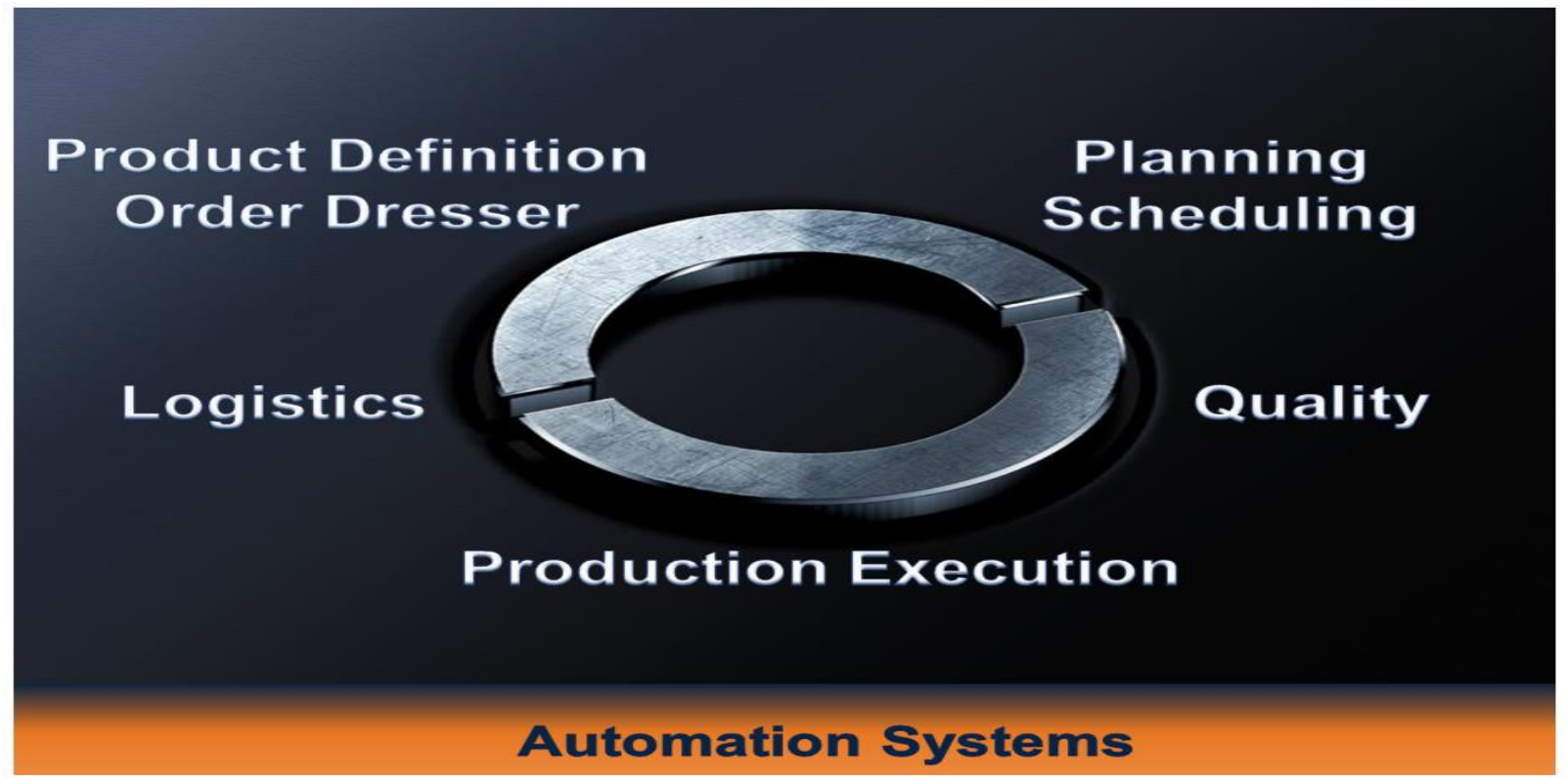

Production Management Module Overview 


\section{MATERIAL AND METHODS}

\section{Product based Production Management Solution}

Tyasa's new production management solution is based on the product PSImetals, which provides a comprehensive set of modules specifically developed for the metals industry already proven in many installations. The product approach (vs. traditional software development) allows the Primetals Technologies project team to bring in its expertise in plant building and extensive process know how to build a broad and robust production management solution through configuration rather than coding, taking advantage of already existing functionality. Hence, custom coding is reduced to a minimum, shortening projection execution time, while keeping the solution's quality high. 


\section{RESULTS AND DISCUSSION}

\subsection{TYASA company profile}

TYASA, Mexico (www.tyasa.com), one of the fastest growing steel producers in North America had its focus in the past on the production of long rolled products. But in 2017 TYASA starts with its first flat production line at its Ixtaczoquitlan site. TYASA will leverage the efficiencies and excess melt capacity of its Quantum Furnace to supply the Castrip thin-strip casting process. The new facility will have the capability to produce 500,000 tons of thin-gauge, high-strength, sheet steel to supply the local manufacturing and construction markets. TYASA's domestic production of highquality sheet steel will allow TYASA to better serve its current customers and grow its business with a more diversified product offering to a broader cross-section of the Mexican market.

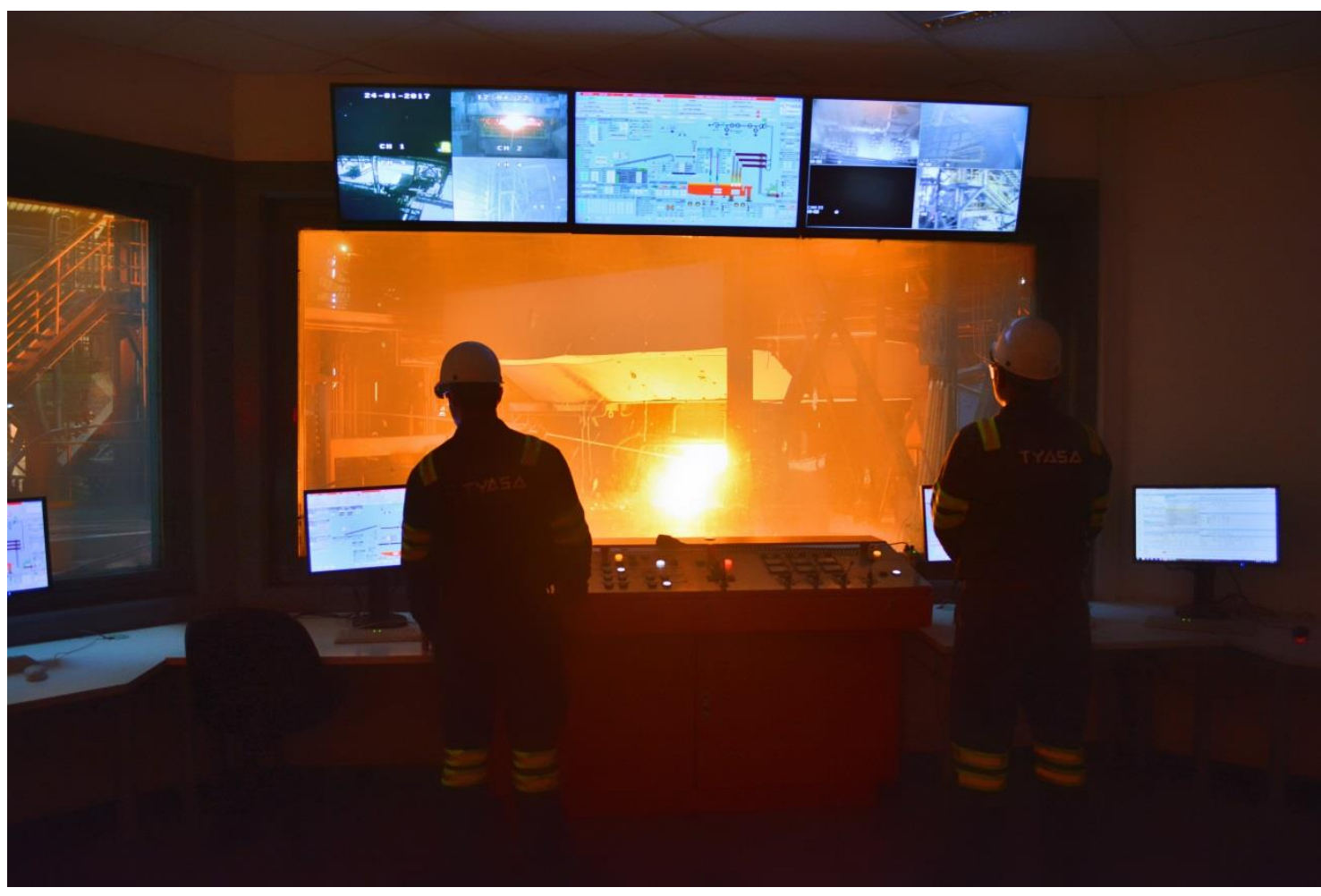

Control pulpit in Tyasa's plant in Ixtaczoquitlan, Mexico. (Photo courtesy of Tyasa).

Castrip is a registered trademark of Castrip LLC. 


\subsection{Production Process}

The Production Management solution covers all work centers from steel making to final coil processing, these are:

- Electric Arc Furnace

- Vacuum Degassing

- Ladle Furnace

- Billet Caster

- Castrip Casting and Hot Coil Rolling

- Tension leveler

- Pickling line

- Reversing Cold Mill

- Batch annealing furnace

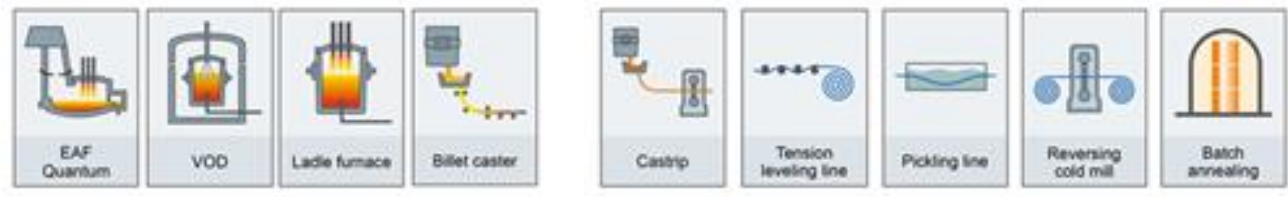

Covered work centers 
Depending on the ordered product various processing ways have to be considered by Level 3 to achieve the target product properties.

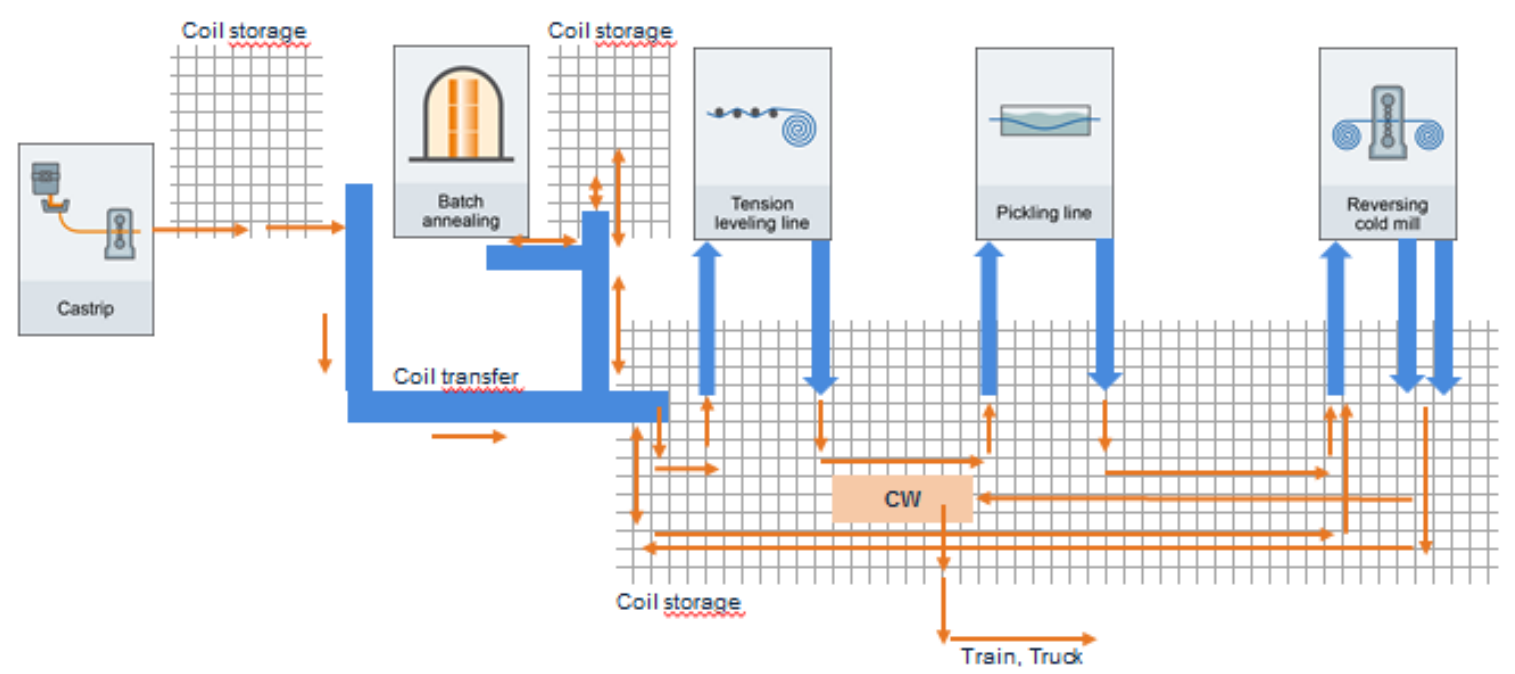

Typical Coil Production Routing

The above figure shows a typical production routing through this plant for a cold rolled coil:

1. The hot rolled coil from Castrip is labelled and temporary stored in the coil bay behind Castrip line before moving via coil transfer to the main coil storage bay.

2. Via transfer conveyor coil is loaded into the tension leveler

3. The next step is to pickle the coil in the pickling line

4. In the reverse cold mill a number of passes are executed

5. Then each coil is treated in one of the two batch annealing furnaces

6. Final passes are executed in the reverse cold mill

7. After coil wrapping the coil is ready for shipping via train or truck 


\subsection{Production Management Modules \& Integration}

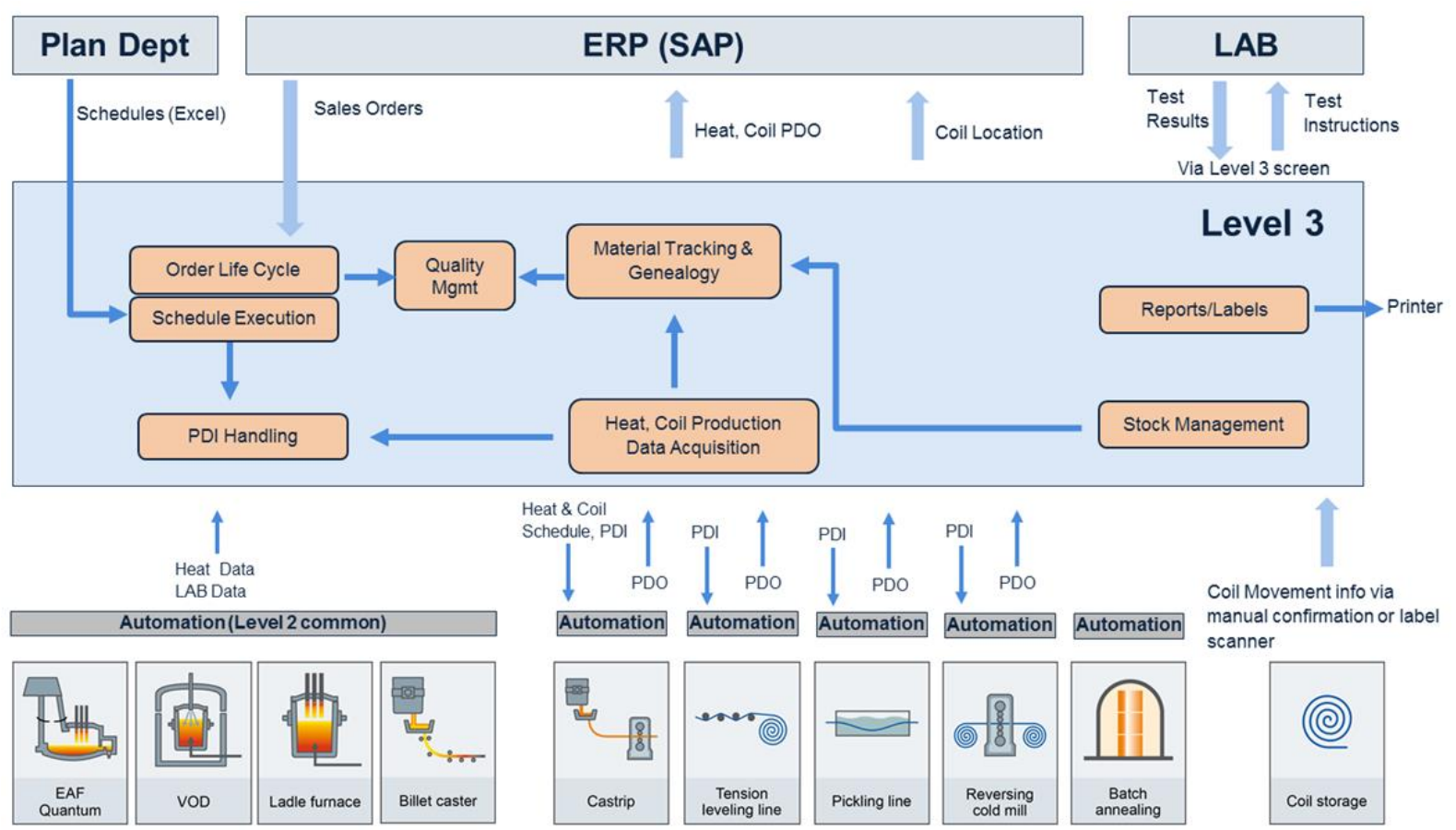

Level 3 modules and system integration

\section{Overview}

The Production Management solution integrates the business level with the automation level by translating sales orders for coils received from SAP into production orders including routing information and process instructions for the production units to allow the product specific setup of the aggregates. Based on released production orders, Tyasa's planning department builds production schedules to be loaded into the system's schedule execution module. After each production step, e.g. producing a new hot rolled coil at Castrip, production results are collected. The horizontal integration of the different automation systems ensures one process step's production feedback is used as part of the process instructions for the next step along the production route. To keep track of work in progress and inventory the solution also consists of a stock management module providing a consistent yard image and easy to use material search functions. 


\section{Order Life Cycle Management}

ERP sends sales orders to Level 3 via standard communication interface.

Each Sales Order is characterized by one certain type of final product (coil) of this production line (same product properties, like steel grade, dimensions) . In addition to that each sales order includes the total weight of qualified products to be produced to fulfill this order.

Out of each sales order Level 3 generates one production order (PO).

A production order ( $\mathrm{PO}$ ) includes a linear sequence of production steps that describe the production process from one stock point to another. A stock point is defined as a place where raw or semi-finished material can be fed into the process chain or where finished or semi- finished products are deployed. For each type of product that can be assigned from a stock point to a PO or that can be deployed as a (semi-) finished product at the last step of the PO, the system typically needs an entry in the material master table.

Product and Routing master information kept in Level 3 are the basis for generating POs.

The Level 3 tracks the status of each order from its receipt throughout production in the Production Line.

Detailed information about:

- Received new/updated orders

- Produced products

- Status of order fulfillment (in progress, completed)

- Track relation between production order and schedule

Events with respect to a PO (e.g. creation, change, allocation of material, status change) are recorded within a PO event history that is available for analysis.

\section{Schedule Execution Management}

In the first phase of this project, production schedules are generated outside the Level 3 - by the planning department - and imported into this module. However the Level 3 allows to manually create (and update/delete) coil production schedules for all coil related processes.

Each schedule describes the sequence of incoming and outgoing material related to a specific process, for example Castrip:

Definition of incoming heat sequence from steel making plant and coil sequence of hot coils to be produced as the output of Castrip process. 


\section{PDI Handling}

PDI (Primary Data Input) are the process instructions for the automation systems created by Level 3 during PO Generation for each coil.

Typical PDI data for coil rolling \& processing:

- Steel grade code

- Chemical analysis values

- Dimensions, weight

- Technological process parameter, like processing temperatures etc.

It is the task of Level 3 to send the PDI for each incoming coil of a specific process, like pickling, to the related process automation system. In normal case the trigger event for PDI sending is the coil announcement by line operator. 


\section{Heat, Coil Production Data Acquisition, Heat, Coil Tracking \& Genealogy}

Aim of Overall Production Tracking is to provide overview information about the status and current location of material pieces (heats, coils) being produced in the Production Line.

The module keeps a list of tracked material pieces based on information (Production Data Output messages) received from the automation systems.

Based on the tracking information, the Level 3 stores the genealogy information, means Level 3 knows the parent-child relation between the produced materials, for example which coil was produced from which heat.
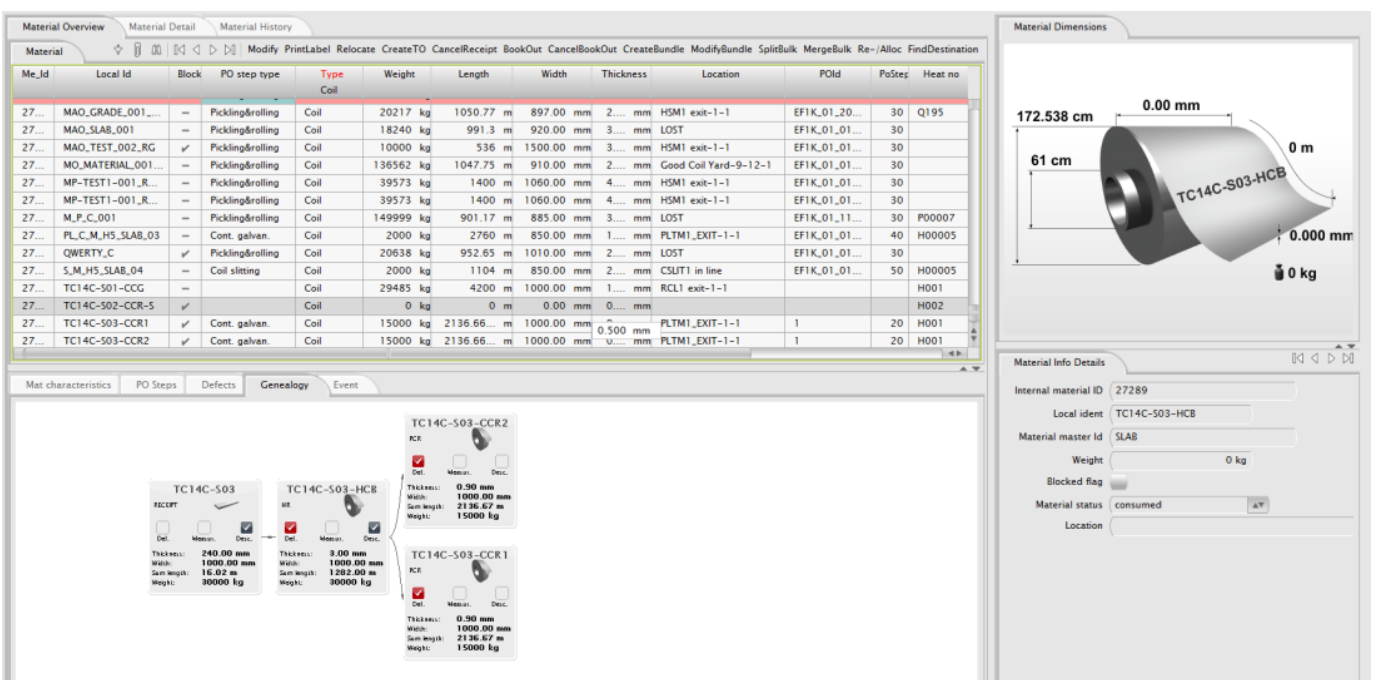

Material Management with graphical genealogy information 


\section{Stock Management}

Once a coil has been treated in a work center of the Production Line, the related automation system sends the coil ID and related coil data (PDO) to the Level 3. Supported by this information of produced coils, the yard operator has to identify each coil at coil yard entry, decides the target location for each coil within the coil yard and confirms the coil transport by input of coil ID and target location via dialog on Level 3 PC on the ground. In addition to that operator can also use a mobile device (Windows based tablet PC) to scan and identify each coil and location. Each coil movement within the yard or move out from the yard has to be confirmed in the same way.

The coil yard topology can be configured via Level 3 dialog.

Therefore, whenever coil yard operator confirms a coil movement he has to use this yard configuration to determine the logical target location of the moved coil.

Based on the confirmed coil movement information the Level 3 provides an inventory list to show all coils currently within the coil yard with their actual logical location. PDO data of each coil can be displayed. In addition to that the list can be filtered for specific coil properties, e.g. to list all coils within the yard belonging to same order. In addition to that a graphical top-down $2 \mathrm{D}$ view is provided to show all coil locations in the coil yard. 


\section{Quality Management}

The Quality Management module is used to support the production process with essential quality functions like quality control and deviation management for the solid part of the process.

Quality Control supports:

- Management of defect type related master data

- Quality data acquisition from the production process during execution like raw material inspection, material defect detection, defect tracking

- Quality checks including automatic Target-Actual-Comparison (TAC) on material characteristics level and automatic checks on test level

Deviation management allows the quality group to handle material issues that have been detected automatically or entered by operators by performing the actions shown in below workflow.

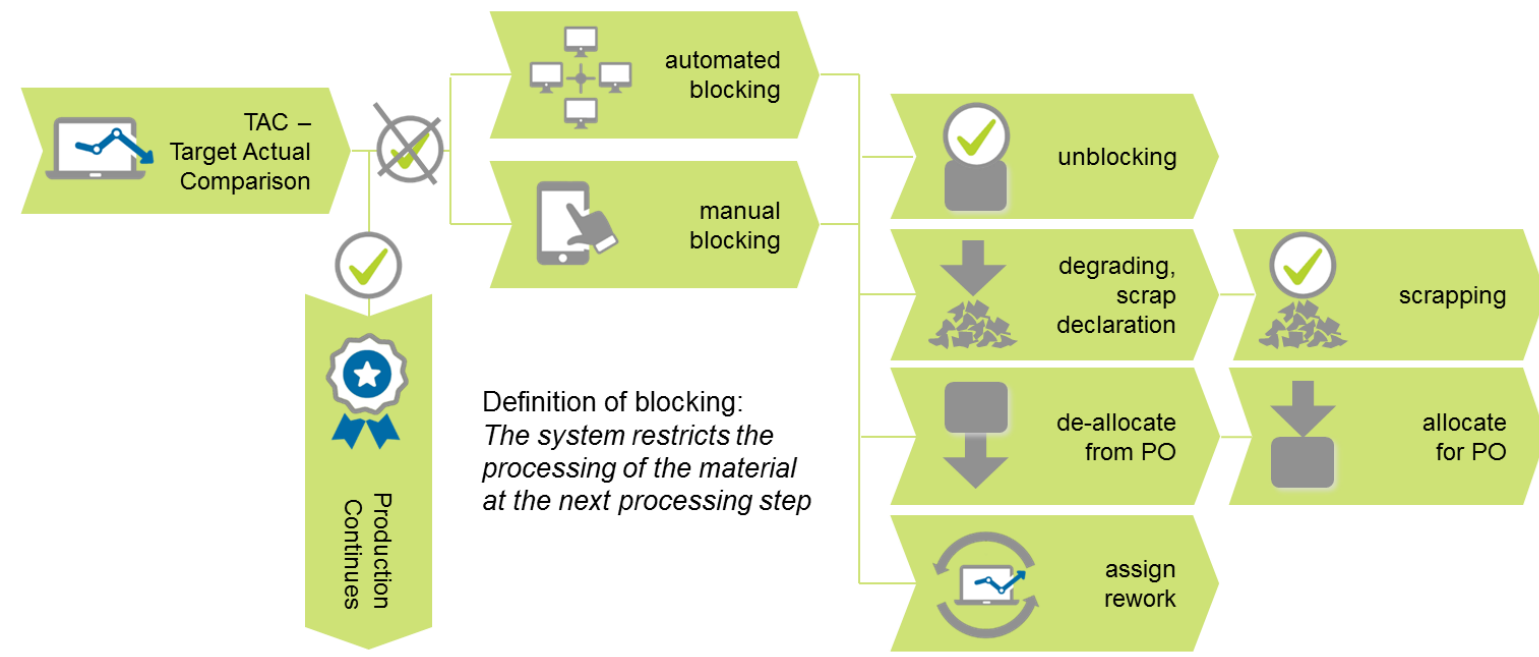

Quality Management workflow 


\section{CONCLUSION}

TYASA's benefits of Primetals' Technologies Production Management solution for its new flat production facility:

- Information transparency for all process stages

- Overall seamless production tracking and genealogy

- TAC (Target-Actual-Comparison) and deviation management of each coil to ensure high quality output

- Horizontal integration with automation systems of production line

- Vertical integration between Business Level and Production Process

- Support the work-to-order concept to minimize stocked products without assigned orders, hence minimizing inventory

- Complete order life cycle management

- Online reporting and KPI-based information

- Highly configurable software product enables customer to adapt/enhance the solution 